Original article

\title{
Position of arm and forearm, and elbow flexion during performance of the sculling technique: Technical recommendation versus actual performance
}

\author{
Lara Elena Gomes \\ Federal University of Vale do São Francisco, Brazil \\ Mônica de Oliveira Melo \\ University of Caxias do Sul, Brazil \\ Victor Wigner Tremea \\ Marcelo La Torre \\ Federal University of Rio Grande do Sul, Brazil \\ Yumie Okuyama da Silva \\ Caruaruense Association of Higher and Technical Education, Brazil \\ Flávio de Souza Castro \\ Jefferson Fagundes Loss \\ Federal University of Rio Grande do Sul, Brazil
}

\begin{abstract}
Sculling motion is a swimming technique executed in a vertical position with the head above the water's surface and, based on the technical recommendation, should be performed maintaining an elbow flexion angle of $90^{\circ}$, arms kept stationary while the forearms move. In order to verify if this recommendation is indeed realistic, the aim of this study was to describe the elbow flexion angle ant its angular velocity, linear speed and range of motion of the shoulder, elbow and wrist during the sculling motion. Data were calculated using three-dimensional kinematic process from underwater video images of ten athletes of synchronized swimming. The results indicate that the arm is relatively stationary and the forearm moves, which agrees with the technical recommendation. However, the elbow flexes and extends, which contradicts the technical recommendation. These findings should be considered when this action is practiced, especially in synchronized swimming, in which sculling motion is a fundamental technique.
\end{abstract}

Keywords: synchronized swimming, kinematic, performance

Resumo - "Posição do braço e antebraço e flexão do cotovelo durante a execução da técnica do palmateio: Recomendação técnica versus o que é realizado na prática." Palmateio realizado na posição vertical, com a cabeça acima da superfície d'água, deve ser realizado mantendo um ângulo de flexão de cotovelo de $90^{\circ}$ e mantendo os braços estacionários enquanto os antebraços movem baseado na recomendação técnica. Com o intuito de verificar se essa recomendação técnica é realmente realizada, o objetivo deste estudo foi descrever o ângulo de flexão do cotovelo, a velocidade angular do cotovelo, a velocidade linear e a amplitude linear de movimento do ombro, do cotovelo e do punho durante o palmateio realizado na posição vertical. Essas variáveis foram calculadas a partir de dados cinemáticos tridimensionais de dez praticantes de nado sincronizado. Os resultados indicam que o braço é relativamente estacionário e o antebraço move-se, concordando com a recomendação técnica, enquanto o cotovelo flexiona e estende, contrariando a recomendação técnica. Esses achados devem ser considerados quando essa ação é trabalhada, especialmente no nado sincronizado, no qual o palmateio é uma técnica fundamental.

Palavras-chave: nado sincronizado, cinemática, desempenho

Resumen - "Posición del brazo y el antebrazo y la flexión del codo durante la ejecución de técnica Sculling: Recomendación técnica frente al que es hecho en la práctica." Sculling realizado en la posición vertical, con la cabeza arriba de la superficie 
del agua, debe ser realizado manteniendo un ángulo de flexión del codo de $90^{\circ} \mathrm{y}$ manteniendo los brazos parados mientras los antebrazos mueven de acuerdo con la recomendación técnica. Para verificar si la recomendación técnica es realmente realizada, el objetivo fue describir el ángulo de flexión del codo, la velocidad angular del codo, la velocidad lineal y la amplitud lineal del movimiento del hombro, codo y muñeca en el sculling en la posición vertical. Las variables fueron calculadas usando datos cinemáticos tridimensionales de 10 practicantes de natación sincronizada. Los resultados indican que lo brazo queda relativamente parado y lo antebrazo mueve, siguiendo la recomendación técnica, mientras el codo flexiona y extiende, contradiciendo la recomendación técnica. Esas conclusiones deben ser consideradas cuando esa acción es trabajada, especialmente en la natación sincronizada, ya que el sculling es una técnica fundamental.

Palabras clave: natación sincronizada, cinemática, rendimiento

\section{Introduction}

Sculling motion is a propulsive action performed in synchronized swimming, water polo and swimming, in which the hands describe a figure of an infinite symbol or an egg-shaped oval (Ito, 2006; Pochon, Arellano \&, Arráez, 2007). The motion is composed of four portions: two translational phases, in-sweep and out-sweep when the hand moves inward and outward respectively, and two rotational phases which are transition phases between the in- and out-sweep phases (Arellano, Terrés-Nicoli \& Redondo, 2006).

This action may provide propulsive force in order to lift the body and/or propel the body on the water. This propulsive force depends on some factors as angular positions of the limbs that perform the movement (Gardano \& Dabnichki, 2006; Lauder $\&$ Dabnichki, 2005). Based on this idea, manuals and books for teacher and coaches contain some technical recommendations about angular positions of the limbs with regard to sculling motion. For example, during a support sculling motion, the elbow flexion angle should be $90^{\circ}$ and the arms should be stationary while the forearms with the hands move inward and outward either if it is done either (a) with head above the water's surface and forearms in pronation, which characterizes a vertical position (Ito, 2006; Thomas, 1990), or (b) with head down and forearms in supination, which characterizes an inverted vertical position (Forbes, 1984; Homma \& Homma, 2006; Fugita, 2010).

In spite of this technical recommendation, Homma and Homma (2006) found that advanced synchronized swimmers flex the elbow during the in-sweep and extend it during the out -sweep phase when performing sculling motion in the inverted vertical position, that is, they do not maintain a flexed elbow at $90^{\circ}$ throughout the sculling motion, but hold their arms relatively stationary while the forearms move.

Although Homma and Homma (2006) expanded knowledge in this area after analyzing sculling motion performed in the inverted vertical position, which is a common position in synchronized swimming, little attention has been paid to sculling motion performed in the vertical position, which may also be performed in synchronized swimming. Consequently, the technical recommendation of manuals and books are still prevailing in sculling motion performed in the vertical position.

On the other hand, the research of Homma and Homma (2006) instigates the following question: does the elbow flexion angle also remain at $90^{\circ}$ while the arm is relatively stationary and the forearm moves during a sculling motion performed in a vertical position? The answer to this question cannot be only useful for advanced synchronized swimmers, who perform this action with the eggbeater kick, but also for beginners who perform this action for lifting the body with or without the eggbeater kick. Moreover, the sculling motion in the vertical position is also performed by water polo players as by swimmers (Pochon, Arellano, \& Arráez, 2007). Therefore, the aim of the present study was twofold: (a) to describe the elbow flexion angle and angular velocity of the elbow to verify whether the elbow remains flexed at $90^{\circ}$ and (b) to describe the linear speed and range of motion of shoulder, elbow and wrist in order to verify if the arm is stationary while the forearm moves during a sculling motion performed in the vertical position according to the technical recommendation.

\section{Methods}

\section{Data acquisition}

To verify whether synchronized swimmers follow the technical recommendation, they were asked to perform sculling motion, maintaining a stationary vertical position, while their performances were recorded.

The sample consisted of ten female right-handed synchronized swimmers (Table 1) that trained at least twice a week and whose classes included 1 hour of exercises outside the pool and 1 hour in the pool. In order to participate in the study, they were required to have at least 6 months of synchorinzed-swimming experience. Their guardians signed informed consent forms. The Ethics Committee of the university where the study was conducted approved this study.

Recording took place in a $25 \mathrm{~m}$ indoor swimming pool. Two digital video cameras (JVC GR-DVL 9800; 1024 x 768 pixels; $50 \mathrm{~Hz}$ ) were positioned behind two glass windows in the same side of the pool, beneath the water level. The distance between the cameras was $11.2 \mathrm{~m}$ and the distance from each camera to the participant was $8.7 \mathrm{~m}$, allowing a lateral view from the right shoulder to the top half of the thigh (Figure 1).

Table 1. Characteristics of the participants ( $\mathrm{SD}$ - standard deviation; $\mathrm{n}=10$ ).

\begin{tabular}{lccc}
\hline & Mean \pm SD & Minimum & Maximum \\
\hline Age (years) & $12.07 \pm 1.95$ & 9.58 & 15.58 \\
Height $(\mathrm{m})$ & $1.52 \pm 0.09$ & 1.34 & 1.35 \\
Body mass $(\mathrm{kg})$ & $48.72 \pm$ & 34.2 & 74.8 \\
& 12.40 & & \\
$\begin{array}{l}\text { Length of practice time } \\
\text { (years) }\end{array}$ & $1.57 \pm 0.45$ & 0.58 & 2.17 \\
\hline
\end{tabular}



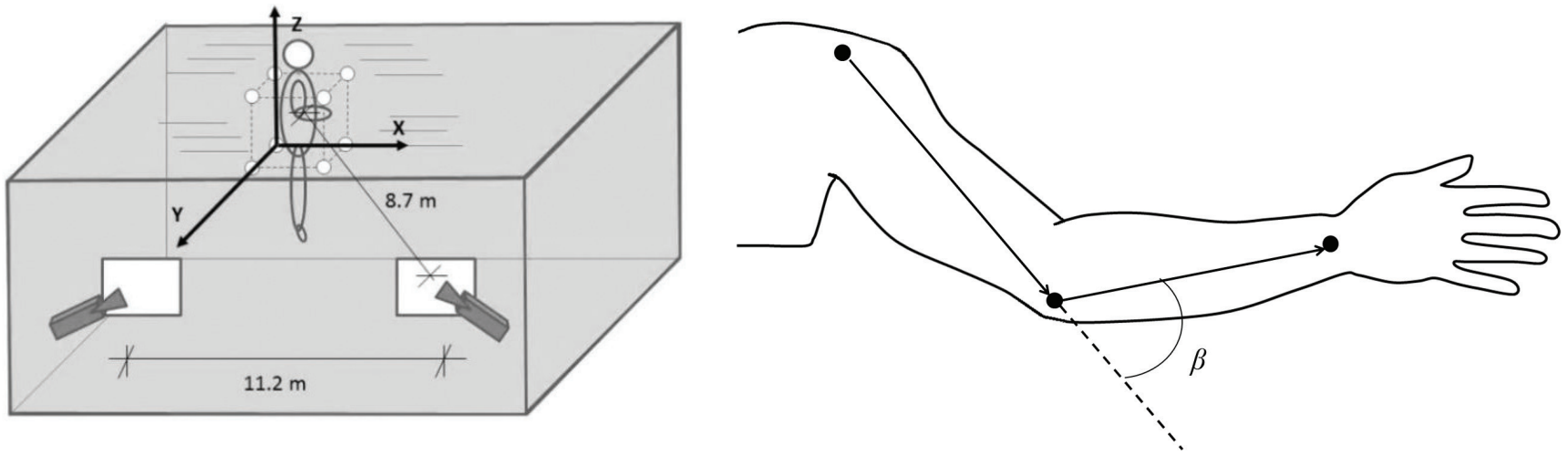

Figure 1. (a) Experimental set-up; (b) Diagram showing the points used for unit vector reconstruction of forearm and arm orientation, where $\beta$ is the elbow flexion angle.

Digital Video for Windows (Dvideow) software was used to track the markers (Figueroa, Leite, \& Barros, 2003). Each camera was connected to an intranet-linked computer to synchronize inter-camera recording. Using a support fixed to the bottom of the pool, a calibration frame $\left(0.80 \times 0.80 \times 0.80 \mathrm{~m}^{3}\right)$ with 12 control object points was placed at the height in the water to be used by the participants (Figure 1).

Landmarks (reflective tape) were placed on the center of wrist joint, on the lateral epicondyle, on the acromion of the right limb and around the distal end of the third finger (Figure 1). Since the cameras were positioned on one side of the pool, only the right limb was analyzed, as in the research of Homma and Homma (2006), since the arm's movement is considered symmetrical when the position of the legs is also symmetrical (Rostkowska, Habiera, \& Antosiak-Cyrak, 2005) and there are no significant differences between right and left hands for sculling motion performed in the vertical position (Pochon, 2004). All tasks were performed within the calibrated volume, and considering the global reference system, the participants were positioned so that the $\mathrm{x}$-axis represented the posterior-anterior direction, the y-axis the medial-lateral direction, and the $\mathrm{z}$-axis the caudal-cranial direction (Figure 1).

Each participant performed a warm-up with sculling motion and familiarization with the experimental conditions. After a 3 -minute rest to avoid fatigue, each one was asked to perform $15 \mathrm{~s}$ of sculling motion at a constant intensity, maintaining a stationary vertical position with the head above the water's surface and with the water at chin-level. This length of time was chosen in order to allow the participants sufficient time to stabilize the movement, while maintenance of the chosen position was the only criterion for standardization of the sculling motion performance.

\section{Data treatment}

Considering that a sculling motion cycle begins when the hand starts to move inward and ends after the hand reverses the direction from outward to inward, three consecutive sculling motion cycles were manually digitized by an experienced digitizer, using Dvideow software. While Homma and Homma (2006) and Rostkowska et al. (2005) analyzed only one sculling motion cycle, we decided to analyze three cycles and the variability between these cycles, since one possible limitation of the present work could be the participants' ages and their times of practice.

Using Dvideow software, three-dimensional coordinates were obtained applying the direct linear transformation method. The accuracy of the measurement system was calculated using the RMS error obtained by comparing the true length of a rod with markers at each end (which was moved throughout the calibrated volume) and the predicted length of the rod, which was estimated from the three-dimensional coordinates reconstructed in 10 fields. The accuracy was equal to $0.005 \mathrm{~m}$. In order to verify the digitizing reliability based on Psycharakis and Sanders (2008) and Figueiredo et al. (2011), one complete cycle of the sculling motion performed by one participant was digitized 10 times for all cameras. Standard deviation (SD) of the points' positions across all digitalizations was calculated as an indication of reliability (Table 2).

Table 2. Standard deviation of all points' positions across 10 digitizations where $\mathrm{x}$-axis represents the posterior-anterior direction, the $\mathrm{y}$-axis the medial-lateral direction, and the $\mathrm{z}$-axis the caudal-cranial direction $(\mathrm{m})$.

\begin{tabular}{lccc}
\hline & $\mathrm{x}$ & $\mathrm{y}$ & $\mathrm{z}$ \\
\hline Center of the wrist joint & 0.0008 & 0.0015 & 0.0013 \\
Lateral epicondyle & 0.0017 & 0.0018 & 0.0023 \\
Acromion & 0.0021 & 0.0013 & 0.0012 \\
Distal end of the third finger & 0.0018 & 0.0014 & 0.0010 \\
\hline
\end{tabular}


All smoothing procedures and calculations were made using Matlab software (7.1). The raw three-dimensional coordinates were smoothed using a seventh order low-pass Butterworth digital filter with cut-offs around 4 and $5 \mathrm{~Hz}$, according to Residual Analysis (Winter, 2005).

The elbow flexion angle $(\beta)$ corresponded to the number of degrees at which the elbow was flexed (Figure 1). It was calculated as the angle between the vector of the distal segment $(D S)$ and the vector of the prolongation of the proximal segment (PPS) (Equation 1):

$$
\beta=\cos ^{-1}\left(\frac{D S}{|D S|} \cdot \frac{P P S}{|P P S|}\right)
$$

(Equation 1)

The DS and the PPS were defined using the following vectors, respectively: elbow to the wrist and the acromion to the lateral epicondyle (Figure 1). Based on Figure 1 and Equation 1 , an elbow flexion angle of $0^{\circ}$ indicates a full extension and the flexion of the elbow increases this angle toward $180^{\circ}$.

The angular velocity of the elbow was calculated using the finite difference of the elbow flexion angle and these velocity data were also smoothed using a seventh order low-pass Butterworth digital filter with cut-off frequencies around 6 and $9 \mathrm{~Hz}$ according to Residual Analysis (Winter, 2005). The linear velocities of the shoulder, elbow and wrist were calculated using the finite difference of the smoothing coordinate data of the point of the acromion, lateral epicondyle and center of the wrist joint respectively. These velocity data were also smoothed using a seventh order low-pass Butterworth digital filter with cut-off frequencies around 7 and $9 \mathrm{~Hz}$ according to Residual Analysis (Winter, 2005). The linear speeds $(S)$ of the shoulder, elbow and wrist was calculated using the smoothing components of the linear velocity $\left(v_{x}, v_{y}\right.$ and $\left.v_{z}\right)$ of each joint, respectively, based on this general equation:

$$
S=\sqrt{v_{x}^{2}+v_{y}^{2}+v_{z}^{2}}
$$

(Equation 2)

The linear range of motion (ROM) of each joint (shoulder, elbow and wrist) was calculated for each direction ( $\mathrm{x}, \mathrm{y}$ and $\mathrm{z}$ ) as the result of the subtraction of the minimum value from maximum value, from the coordinate data of the point of the acromion, lateral epicondyle and center of the wrist joint respectively. The linear ROM of each direction was estimated for each cycle, and an average of these three cycles was calculated for each participant.

The time of each cycle of sculling motion was normalized, and the average cycle of the three cycles was calculated for the elbow flexion angle, angular velocity of the elbow and linear speed of the shoulder, elbow and wrist. The average cycle was divided into four phases: in-sweep, transition phase from in-sweep to out-sweep, out-sweep and transition phase from out-sweep to in-sweep. The transition phases were characterized as occuring when the hand rapidly rotates and reverses direction (Arellano et al., 2006) and the in-sweep and out-sweep phases were characterized as occuring when the hand moves inward and outward respectively (Homma \& Homma, 2006).
Based on the average cycle of the third finger coordinates for each participant, the $\mathrm{y}$ and $\mathrm{z}$ coordinates were used to divide these phases. Considering the participant's location in the global reference system, a reduction in the y coordinate indicates approximation of the hand to the body (indicating an in-sweep phase) and an increase indicates the hand moving away from the body (an out-sweep phase). Peaks in the $\mathrm{z}$-axis were associated with hand rotations (indicating transition phases).

In this study, in normalized time, the in-sweep starts at $1 \%$, while $100 \%$ represents the end of the transition phase from out-sweep to in-sweep. To describe the elbow flexion angle, angular velocity of the elbow and linear speed of the shoulder, elbow and wrist, the average for these variables in each phase was obtained from each participant's average cycle.

\section{Statistical analysis}

The normality of the data was evaluated using Shapiro-Wilk test. Even if the normality was not confirmed, parametric statistics were applied, because nonparametric analysis lacks power for small sample sizes (Hopkins et al., 2008). Just the normality of the angular velocity of the elbow in the transition phases was violated. Moreover, there was a missing case since a participant did not present the transition phase from in-sweep to out-sweep according to the established criterion.

Afterwards, multiple one-way repeated-measures ANOVA were used to compare the average elbow flexion angle, angular velocity of the elbow and linear speed of the shoulder, elbow and wrist between the phases; to compare the linear speed and ranges of motion between the shoulder, elbow and wrist; to compare the linear ranges of motion of shoulder, elbow and wrist between the directions. If the assumption of sphericity was violated according to Mauchly's test, the degrees of freedom were corrected using Greenhouse-Geisser. Bonferroni Post Hoc test was used to identify differences between the phases, joints and directions respectively.

Since the participants were young and did not have much practice time, the linear ranges of motion of shoulder, elbow and wrist of each cycle and the variability evaluated using the coefficient of variation $(\mathrm{CV})$, which is the ratio of standard deviation to mean times 100 , of the elbow flexion angle, angular velocity of the elbow, linear speeds of the shoulder, elbow and wrist of each cycle were compared using multiple one-way repeated-measures ANOVA. As mentioned before, the normality and sphericity of the data were evaluated using Shapiro-Wilk and Mauchly's tests respectively. Even if the normality was not confirmed, parametric statistics were applied and this happened with just 3 variables of a total 39 variables. If the assumption of sphericity was violated, the degrees of freedom were corrected using Greenhouse-Geisser. Bonferroni Post Hoc test was used to identify differences between the cycles.

The level of significance adopted for these tests was $\alpha<0.05$. All statistical procedures were conducted using SPSS software (version 17.0 for Windows) and the statistical results will be presented in accordance with Field (2009). 
Table 3. Average, standard deviation (SD), lower and upper boundaries of confidence interval (CI) of shoulder, elbow and wrist's linear speed $(\mathrm{m} / \mathrm{s})$ for each phase of the average cycle and statistical results of the comparison between the joints' speeds in each phase. The same superscript sign indicates differences between joints' speed in the same phase.

\begin{tabular}{|c|c|c|c|c|c|c|c|}
\hline \multirow[b]{2}{*}{ Phase } & \multicolumn{2}{|c|}{ Shoulder's speed } & \multicolumn{2}{|c|}{ Elbow's speed } & \multicolumn{2}{|c|}{ Wrist's speed } & \multirow[b]{2}{*}{ Statistical results } \\
\hline & $\begin{array}{l}\text { Average } \\
\pm \mathrm{SD}\end{array}$ & $\mathrm{CI}$ & $\begin{array}{l}\text { Average } \\
\pm \mathrm{SD}\end{array}$ & $\mathrm{CI}$ & $\begin{array}{l}\text { Average } \\
\pm \mathrm{SD}\end{array}$ & $\mathrm{CI}$ & \\
\hline In-sweep & $\begin{aligned} & 0.17 \\
\pm & 0.04^{* \dagger}\end{aligned}$ & $\begin{array}{c}0.14- \\
0.19\end{array}$ & $\begin{array}{c}0.38 \\
\pm 0.06^{* \ddagger}\end{array}$ & $\begin{array}{c}0.33- \\
0.43\end{array}$ & $\begin{array}{l}1.12 \\
\pm 0.11^{\dagger+}\end{array}$ & $\begin{array}{c}1.04- \\
1.20\end{array}$ & $\begin{array}{c}F(2,18)=512.68, p<0.001, \omega^{2}=0.96 \\
{ }^{* \dagger \neq} p<0.001\end{array}$ \\
\hline $\begin{array}{l}\text { Transition from in-sweep } \\
\text { to out-sweep }\end{array}$ & $\begin{aligned} & 0.13 \\
\pm & 0.05^{* \dagger}\end{aligned}$ & $\begin{array}{c}0.09- \\
0.17\end{array}$ & $\begin{aligned} & 0.42 \\
\pm & 0.10^{* *}\end{aligned}$ & $\begin{array}{c}0.34- \\
0.50\end{array}$ & 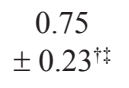 & $\begin{array}{c}0.57- \\
0.92\end{array}$ & $\begin{array}{c}F(1.19,9.52)=58.14, p<0.001, \omega^{2}=0.79 \\
{ }^{*} p<0.001,{ }^{\star} p=0.005\end{array}$ \\
\hline Out-sweep & $\begin{aligned} & 0.16 \\
\pm & 0.05^{* \dagger}\end{aligned}$ & $\begin{array}{c}0.12- \\
0.19\end{array}$ & $\begin{aligned} & 0.38 \\
\pm & 0.07^{* *}\end{aligned}$ & $\begin{array}{c}0.33- \\
0.44\end{array}$ & $\begin{array}{l}0.96 \\
\pm 0.16^{\dagger+}\end{array}$ & $\begin{array}{c}0.84- \\
1.09\end{array}$ & $\begin{array}{c}F(2,18)=138.61, p<0.001, \omega^{2}=0.85 \\
{ }^{*} p<0.001\end{array}$ \\
\hline $\begin{array}{l}\text { Transition from out-sweep } \\
\text { to in-sweep }\end{array}$ & $\begin{aligned} & 0.17 \\
\pm & 0.04^{* \dagger}\end{aligned}$ & $\begin{array}{c}0.14- \\
0.20\end{array}$ & $\begin{aligned} & 0.40 \\
\pm & 0.06^{*}\end{aligned}$ & $\begin{array}{c}0.36- \\
0.45\end{array}$ & $\begin{array}{c}0.63 \\
\pm 0.09^{\text {t* }}\end{array}$ & $\begin{array}{c}0.57- \\
0.70\end{array}$ & $\begin{array}{c}F(2,18)=57.03, p<0.001, \omega^{2}=0.66 \\
{ }^{*} p=0.001,{ }^{\dagger} p<0.001\end{array}$ \\
\hline
\end{tabular}

\section{Results}

Based on the technical recommendation, the elbow flexion angle should be $90^{\circ}$ and arms should be stationary while the forearms move throughout the sculling motion performed in the vertical position. The results of the present study regarding the joints' linear speed and ROM show that the shoulder was more stationary than the elbow and both joints were more stationary than the wrist. That is, the shoulder's linear speed was lower than elbow's linear speed and both were lower than the wrist's linear speed in all the phases (Table 3). As well as the shoulder's linear ROM was lower than elbow's linear ROM and both were lower than the wrist's linear ROM in all directions (Table 4). Based on these results, the technical recommendation about holding stationary arms while the forearms move is reasonable.

In comparing the joints' linear speed between the phases (Table 3), it was also possible to note that there was a significant effect of the phases on the shoulder's linear speed, $F(3$, $24)=5.80, p=0.004, \omega^{2}=0.09$, but the post hoc did not show difference between the phases; there was not a significant ef- fect of the phases on the elbow's linear speed, $F(3,24)=0.88$, $p=0.46, \omega^{2} \approx 0.000$, but there was a significant effect of the phases on the wrist's linear speed, $F(1.55,12.41)=24.15, p<0.001$, $\omega^{2}=0.55$, where the wrist's linear speed in the in-sweep phase was higher than in the transition phase from in to out-sweep ( $p=0.004)$, out-sweep $(p=0.007)$ and transition phase from out to in-sweep $(p<0.001)$ and the wrist's linear speed in the out-sweep phase was higher than in the transition phase from in to out-sweep $(p=0.011)$ and in the transition phase from out to in-sweep $(p=0.010)$.

In comparing the joints' linear ROM between the directions (Table 4), it was also possible to note that there was not a significant effect of the directions on the shoulder's linear ROM, $F(2,18)=1.32, p=0.30, \omega^{2}=0.02$ and on the elbow's linear ROM, $F(2,18)=0.87, p=0.43, \omega^{2}<0.001$. On the other hand, there was a significant effect of the directions on the wrist's linear ROM, $F(2,18)=31.26, p=0.001, \omega^{2}=0.56$, where the wrist's linear ROM at medial-lateral direction was higher than at posterior -anterior $(p=0.003)$ and caudal-cranial directions $(p<0.001)$ and the wrist's linear ROM at posterior-anterior direction was higher than at caudal-cranial direction $(p=0.006)$.

Table 4. Average, standard deviation (SD), lower and upper boundaries of confidence interval (CI) of shoulder, elbow and wrist's linear range of motion (ROM) for each direction and statistical results of the comparison between the joints' ROM in each direction. The same superscript sign indicates differences between joints' ROM in the same direction.

\begin{tabular}{|c|c|c|c|c|c|c|c|}
\hline \multirow[b]{2}{*}{ Direction } & \multicolumn{2}{|c|}{ Shoulder's ROM (m) } & \multicolumn{2}{|c|}{ Elbow’s ROM (m) } & \multicolumn{2}{|c|}{ Wrist's ROM (m) } & \multirow[b]{2}{*}{ Statistical results } \\
\hline & $\begin{array}{l}\text { Average } \\
\pm \mathrm{SD}\end{array}$ & $\mathrm{CI}$ & $\begin{array}{l}\text { Average } \\
\pm \mathrm{SD}\end{array}$ & $\mathrm{CI}$ & $\begin{array}{l}\text { Average } \\
\pm \mathrm{SD}\end{array}$ & $\mathrm{CI}$ & \\
\hline Posterior-anterior & $\begin{aligned} & 0.03 \\
\pm & 0.01^{* \dagger}\end{aligned}$ & $\begin{array}{c}0.02- \\
0.04\end{array}$ & $\begin{aligned} & 0.07 \\
\pm & 0.03^{*}\end{aligned}$ & $\begin{array}{c}0.05- \\
0.09\end{array}$ & $\begin{array}{l}0.16 \\
\pm 0.05^{\dagger *}\end{array}$ & $\begin{array}{c}0.13- \\
0.20\end{array}$ & $\begin{array}{c}F(2,18)=81.82, p<0.001, \omega^{2}=0.70 \\
{ }^{*} p=0.001,{ }^{*} p<0.001\end{array}$ \\
\hline Medial-lateral & $\begin{aligned} & 0.03 \\
\pm & 0.004^{* \dagger}\end{aligned}$ & $\begin{array}{c}0.027- \\
0.033\end{array}$ & $\begin{aligned} & 0.06 \\
\pm & 0.02^{*+}\end{aligned}$ & $\begin{array}{c}0.05- \\
0.07\end{array}$ & $\begin{array}{l}0.21 \\
\pm 0.04^{\dagger+}\end{array}$ & $\begin{array}{c}0.18- \\
0.25\end{array}$ & $\begin{array}{c}F(1.13,10.20)=143.78, p<0.001, \omega^{2}=0.92 \\
{ }^{*+\downarrow} p<0.001\end{array}$ \\
\hline Caudal-cranial & $\begin{array}{c}0.02 \\
\pm 0.009^{* \dagger}\end{array}$ & $\begin{array}{c}0.018- \\
0.031\end{array}$ & $\begin{aligned} & 0.07 \\
\pm & 0.02^{* \ddagger}\end{aligned}$ & $\begin{array}{c}0.05- \\
0.09\end{array}$ & $\begin{array}{l}0.10 \\
\pm 0.04^{\dagger+}\end{array}$ & $\begin{array}{c}0.07- \\
0.12\end{array}$ & $\begin{array}{c}F(2,18)=33.36, p<0.001, \omega^{2}=0.66 \\
{ }^{* *} p<0.001,{ }^{\ddagger} p=0.028\end{array}$ \\
\hline
\end{tabular}


Table 5. Average, standard deviation (SD), lower and upper boundaries of confidence interval (CI) of angular velocity of elbow (degree/s) and elbow flexion angle (degree) for each phase of the average cycle.

\begin{tabular}{lcccc}
\hline & \multicolumn{2}{c}{ Angular velocity } & \multicolumn{2}{c}{ Elbow flexion angle } \\
\hline Phase & $\begin{array}{c}\text { Average } \pm \\
\text { SD }\end{array}$ & CI & $\begin{array}{c}\text { Average } \pm \\
\text { SD }\end{array}$ & CI \\
\hline In-sweep & $174 \pm 43$ & $141-208$ & $77 \pm 18$ & $63-91$ \\
& & & & \\
$\begin{array}{l}\text { Transition from in } \\
\text { to out-sweep }\end{array}$ & $-40 \pm 114$ & $-128-47$ & $103 \pm 20$ & $88-$ \\
& & & & 118 \\
$\begin{array}{l}\text { Out-sweep } \\
\begin{array}{l}\text { Transition from } \\
\text { out to in-sweep }\end{array}\end{array}$ & $-128 \pm 41$ & $-160--97$ & $87 \pm 21$ & $71-$ \\
\hline
\end{tabular}

The differences in the wrist's linear speed between the phases and the wrist's linear ROM between the directions, as well as the lack of differences of the shoulder and elbow's linear speeds between the phases and shoulder's and elbow's linear ROM between the directions reinforce the technical recommendation about holding stationary arms while forearms move. That is, the shoulder and elbow perform small movements, which are similar between the phases and directions, while the wrist moves more in some specific phases and directions (Tables 3 and 4). However, although this part of the technical recommendation may be accepted, the part about maintaining the elbow flexion angle at $90^{\circ}$ may not be accepted.

Table 5 presents the angular velocity of the elbow, where a positive velocity indicates that the elbow is flexing and a ne-

Table 6. Statistical results of the comparison of the average of shoulder, elbow and wrist's linear ROM of each direction between the cycles and the comparisons of the coefficient of variation $(\mathrm{CV})$ of the elbow flexion angle, angular velocity of elbow, and linear speeds of shoulder, elbow and wrist between the cycles.

\begin{tabular}{lc}
\hline Variables & Statistical results \\
\hline Shoulder' ROM at x-axis & $F(2,18)=2.11, p=0.15, \omega^{2} \approx 0.00$ \\
Elbow' ROM at x-axis & $F(2,18)=2.61, p=0.99, \omega^{2} \approx 0.00$ \\
Wrist's ROM at x-axis & $F(2,18)=1.64, p=0.22, \omega^{2}=0.02$ \\
Shoulder' ROM at y-axis & $F(2,18)=0.60, p=0.56, \omega^{2}=-0.02$ \\
Elbow' ROM at y-axis & $\begin{array}{l}F(2,18)=3.94, p=0.04, \omega^{2}=0.22, \text { no } \\
\text { difference was noted using post hoc }\end{array}$ \\
Wrist's ROM at y-axis & $F(2,18)=1.51, p=0.25, \omega^{2}=0.03$ \\
Shoulder' ROM at z-axis & $F(2,18)=0.27, p=0.77, \omega^{2}=0.03$ \\
Elbow' ROM at z-axis & $F(2,18)=0.81, p=0.46, \omega^{2} \approx 0.00$ \\
Wrist's ROM at z-axis & $F(2,18)=0.61, p=0.56, \omega^{2}=-0.04$ \\
CV of elbow flexion angle & $F(2,18)=1.64, p=0.22, \omega^{2}=0.02$ \\
CV of angular velocity of & $F(2,18)=1.51, p=0.25, \omega^{2}=0.01$ \\
elbow & $F(2,18)=3.16, p=0.07, \omega^{2}=0.13$ \\
CV of shoulder's speed & $F(2,18)=0.28, p=0.76, \omega^{2}=-0.06$ \\
CV of elbow's speed & $F(2,18)=0.13, p=0.88, \omega^{2}=-0.04$ \\
\hline CV of wrist's speed &
\end{tabular}

gative velocity indicates that the elbow is extending. As it can be seen in Table 5, there was a significant effect of the phases on the angular velocity of elbow, $F(3,24)=30.307, p<0.001$, $\omega^{2}=0.63$, indicating that the elbow flexes in the in-sweep phase and extends in the other subsequent phases. Consequently, the angular velocity of the elbow was higher in the in-sweep phase than in the transition phase from in to out-sweep $(p=0.008)$, in the out-sweep $(p<0.001)$ and in the transition phase from out to in-sweep $(p<0.001)$.

In order to analyze more carefully, the elbow flexion angle was compared between the phases (Table 5) where a higher angle indicates that the elbow was more flexed. Based on these analyses, there was a significant effect of the phases on the average elbow flexion angle, $F(1.409,11.274)=89.035, p<0.001, \omega^{2}=0.48$, where the angle in the transition phase from in to out-sweep was higher than in the in-sweep $(p<0.001)$, in the out-sweep $(p=0.006)$ and in the transition phase from out to in-sweep $(p<0.001)$, as well as the transition phase from out to in-sweep presented lower values than the in-sweep $(p=0.004)$ and out-sweep $(p<0.001)$. These results about the angular position reinforce the finding that the technical recommendation about maintaining the elbow flexion angle at $90^{\circ}$ may not be accepted.

Table 6 presents the comparisons of the average of the shoulder, elbow and wrist's linear ROM between the cycles and the comparisons of the CVs of the elbow flexion angle, angular velocity of the elbow, linear speed of the shoulder, elbow and wrist between the cycles. Since these comparisons were made in order to verify the variability between the cycles due to the characteristics of the sample, data as averages and standard deviations of the CVs were not presented. The statistical results indicate that there is no difference between the cycles, that is, although the participants were young and did not have much practice time, all variables' behavior remained stable during the three cycles.

\section{Discussion}

The discrepancy between the technical recommendation regarding sculling motion, as described in books and manuals for teachers and coaches, and what is performed in practice has already been investigated. For example, Pochon, Arellano and Arráez (2007) and Arellano (2011) have noted that the path of the hand in the sculling motion performed in the vertical position is not a perfect infinite symbol, which is described in books and manuals.

Furthermore, prior work has documented that advanced synchronized swimmers keep their arms relatively stationary, which may be considered in accordance with the technical recommendation, while they flex the elbow during the in-sweep and extend it during the out-sweep phase during sculling motion in the inverted vertical position, contradicting the technical recommendation (Homma \& Homma, 2006). On the other hand, to our knowledge, all the variables analyzed in the present study considering a sculling motion performed in the vertical position, which is also performed in synchronized swimming, had not been investigated yet. 
The present study has focused on analyzing the elbow flexion angle and angular velocity of the elbow in order to verify whether the elbow remains flexed at $90^{\circ}$ and the linear speed and range of motion of the shoulder, elbow and wrist in order to verify if the arm is stationary while the forearm moves during the sculling motion performed in the vertical position. For these purpose, three-dimensional kinematic data from underwater video analysis were used. Accordingly, the results confirm the findings of Homma and Homma (2006), that is, the arm is kept relatively stationary while the forearm moves and the elbow flexes in the in-sweep and extends in the out-sweep phase (Tables 3, 4 and 5).

Homma and Homma (2006) verified that the arm is kept relatively stationary in their analysis of the upper arm angle, which was calculated as the angle between a vector from shoulder to elbow and a vector from shoulder to greater trochanter. The range of this angle was on average smaller than $30^{\circ}$ for most advanced synchronized swimmers. The authors also concluded that the sculling motion is performed by the forearms and hands, but that the hands lead the movement in the in-sweep phase while the forearms and hands move as a unit in the out-sweep phase. Although the present study has not analyzed the same variables analyzed by Homma and Homma (2006), the results (Tables 3 and 4) provide support for accepting the technical recommendation in part, that is, in the sculling motion performed in the vertical position, the arms should be relatively stationary.

The discussion about the differences found in the linear speed and ROM of the wrist between the phases and directions respectively is not within the scope of this study, but these results also provides support to the portion of the technical recommendation mentioned above. That is, the shoulder and elbow present a stable behavior while the wrist presents a different behavior between the phases and directions, which indicates that, while the arm is relatively stationary, the forearm moves during the sculling motion.

Moreover Homma and Homma (2006) found an average elbow flexion angle of $80^{\circ}$ in the in-sweep, which is similar to the findings of the present study, and $45^{\circ}$ in the out-sweep, which is slightly smaller than what it was noted by the present study (Table 5). Aside from Homma and Homma (2006), Rostkowska et al. (2005) also investigated the elbow flexion angle in the inverted vertical position and found a variation in the angle, but the authors noted that the best synchronized swimmers presented smaller angular changes during the movement. However, Rostkowska et al. (2005) used only one camera to analyze the sculling motion, which is a three-dimensional movement. Thus, the result of this last study is not probably accurate.

Homma and Homma (2006) also noted that the elbow flexes in the in-sweep phase and extends in the out-sweep phase. This result is in accordance with the present study, since the angular velocity of the elbow was positive in the in-sweep phase, indicating that the elbow flexes, and negative in the other subsequent phases, indicating that the elbow extends (Table 5). Consequently, the part of the technical recommendation about maintaining the elbow flexion angle at $90^{\circ}$ may not be accepted.

Homma and Homma (2005) also analyzed another position in which a sculling motion is performed in synchronized swimming. In this last study, they have investigated the sculling motion in a back layout position performed by 10 Olympic synchronized swimmers and noted that the elbow flexes in the in-sweep phase and extends in the out-sweep phase, while the arm is relatively stationary.

Therefore, based on the results of the present study, which are in accordance with prior works that have analyzed other positions (Homma \& Homma, 2005; Homma \& Homma, 2006), synchronized swimmers, when performing sculling motion in the vertical position, should hold their arms relatively stationary and move their forearms while the elbows flex in the in-sweep phase and extend in the out-sweep phase.

Keeping arms relatively stationary may likely help in the body's stability, which is very important in synchronized swimming since athletes should be able to maintain a steady height in the water. Furthermore, Homma and Homma (2006) suggested that synchronized swimmers extend the elbows as the upper arm angle increases, that is, in order to keep the forearms in a horizontal position, the elbows extend or flex in accordance with the upper arm angle. Therefore, the recommendation presented in manuals and books for teachers and coaches (Forbes, 1984; Fugita, 2010; Thomas, 1990) is based on a situation in which the arms are completely stationary and the elbows are positioned near the body while the elbow angle is fixed at $90^{\circ}$, which allow a horizontal position of the forearms. According to Homma and Homma (2006), this horizontal position of the forearms is recommended because, based on studies of swimming propulsion, it might aid in producing more lift force as a result of the movement performed by forearms and hands in a better orientation for this purpose (Berger, Groot, \& Hollander, 1995; Sanders, 1999; Schleihauf, 1979).

One possible limitation of the present work might have been the participants' ages and amounts of practice time. However, they have presented a stable behavior in the variables between the three cycles (Table 6). Although motor variability is a common feature of human movement (Latash, Scholz, \& Schöner, 2002), it tends to decrease with practice (Müller, Sternad, \& Frank, 2007), that is, the participants already had enough practice time and were able to perform a stable sculling motion. In contrast, Rostkowska et al. (2005) and Homma and Homma (2006) analyzed only one cycle, although their sample comprised advanced synchronized swimmers.

Further investigations should focus on the effects of different intensities on the kinematic variables investigated by the present study. These different intensities may be evaluated using an addition of some loads as Pochon, Arellano, and Arráez (2007) analyzed, or with an arm out of the water and performing eggbeater kick, which is a common practice in synchronized swimming, or different intensities may be evaluated using different perception of efforts but without adding loads. In the present study, the participants were asked to maintain a position with the water at chin-level in order to maintain all landmarks in the water since just two cameras were used. Thus, in order to develop the last two ideas, more than two cameras outside of the water's are needed, because the shoulder may go above the water surface.

Another subject that needs more attention is upper-limb symmetry during sculling motion and its relationship with lateral 
dominance. In the current study, the sample was composed of right-handed synchronized swimmers and just the right arm was analyzed. Consequently, future work should focus on upper-limb symmetry, exploring a variety of kinematic variables and their relationships with sculling motion performance.

The results of the present study indicate that the arm is relatively stationary while the forearm moves during the sculling motion, which is in accordance with the technical recommendation. However, the results also indicate that the elbow flexes in the in-sweep and extends in the out-sweep phase when sculling motion is performed in the vertical position, contradicting the technical recommendation of maintaining a $90^{\circ}$ angle throughout the movement. Thus, the findings of the present study do not totally agree with the recommendations described in manuals and books for teachers and coaches.

On the one hand, someone may think that the recommendations described in manuals and books may be appropriate for beginners, who may have some difficulty in controlling all the aspects of the movement. On the other hand, manuals and books intend to present the best technical movement as well as they may present tips to teach the movement. However, in order to describe the best tips/ways to teach, it would be very beneficial a further work that focus on the influence of different methods of teaching on the sculling motion performance.

Thus, the discrepancy between the described technical recommendation and what is performed into practice needs to be considered when the sculling motion is taught, especially in synchronized swimming since this action is a fundamental technique in this sport (Homma \& Homma, 2005). Furthermore, the findings of the present study also reinforce the need to investigate the sculling motion technique in order to improve the teaching and the correction of this action.

\section{References}

Arellano, R. (2011). Transferring applied hydrodynamics to technical training: "The Sculling Project". Portuguese Journal of Sports Sciences, 11 (suppl. 3), 69-72.

Arellano, R., Terrés-Nicoli, J., \& Redondo, J. (2006). Fundamental Hydrodynamics of Swimming Propulsion. Portuguese Journal of Sports Sciences, 6(suppl. 2), 15-20.

Berger, M. A. M., Groot, G., \& Hollander, A. P. (1995). Hydrodynamic drag and lift forces on human hand/arm models. Journal of Biomechanics, 28, 125-133. doi: 10.1016/0021-9290(94)00053-7

Figueroa, P. J., Leite, N. J., \& Barros, R. M. L. (2003). A flexible software for tracking of markers used in human motion analysis. Computer Methods and Programs in Biomedicine, 72(2), 155-165. doi: 10.1016/S0169-2607(02)00122-0

Figueiredo, P., Machado, L., Vilas-Boas, J. P., \& Fernandes, R. (2006). Reconstruction error of calibration volume's coordinates for 3D swimming kinematics. Journal of Human Kinetics, 29, 35-40.

Field, A. (2009). Discovering Statistics Using SPPSS. London: SAGE Publications Ltd.

Forbes, M. S. (1984). Coaching Synchronized Swimming Effectively. Champaign: Human Kinetics Publishers.

Fugita, M. (2010). Fundamentos do nado sincronizado: estabilizar e deslocar. In P. H. L. da Costa, Natação e Atividades Aquáticas: subsidios para o ensino (pp. 71-88). Barueri: Manole.

Gardano, P., \& Dabnichki, P. (2006). On hydrodynamics of drag and lift of the human arm. Journal of Biomechanics, 39(15), 2767-2773. doi: 10.1016/j.jbiomech.2005.10.005

Homma, M., \& Homma, M. (2005). Sculling Techniques in Synchronized Swimming. In Quing Wang (Ed.), XIII International Symposium on Biomechanics in Sports (pp. 932-935). Beijing: China Institute of Sport Science.

Homma, M., \& Homma, M. (2006). Support Scull Techniques of Elite Synchronized Swimmers. Portuguese Journal of Sports Sciences, 6 (suppl. 2), 220-223.

Hopkins, W. G., Marshall, S. W., Batterham, A. M., \& Hanin, J. (2009). Progressive Statistics for Studies in Sports Medicine and Exercise Science. Medicine and Science in Sports and Exercise, 41(1), 3-12. doi: $10.1249 / \mathrm{msss} .0 \mathrm{~b} 013 \mathrm{e} 311818 \mathrm{cb} 278$

Ito, S. (2006). Fundamental Fluid Dynamic Research on Configuration of the Hand Palm in Synchronized Swimming. Portuguese Journal of Sports Sciences, 6 (suppl. 2), 45-48.

Latash, M. L., Scholz, J. P., \& Schöner, G. (2002). Motor Control Strategies Revealed in the Structure of Motor Variability. Exercise and Sports Sciences Reviews, 30(1), 26-31.

Lauder M. A., \& Dabnichki, P. (2005). Estimating propulsive forces sink or swim? Journal of Biomechanics, 38(10), 1984-1990. doi: 10.1016/j.jbiomech.2005.05.026

Müller, H., Sternad, D., \& Frank T.D. (2007). Variability, covariation, and invariance with respect to coordinate systems in motor control: reply to Smeets and Louw (2007). Journal of Experimental Psychology: Human Perception and Performance, 33, 250-255. doi: 10.1037/0096-1523.33.1.250

Pochon, A. (2004). 3D Analysis of Vertical Sculling (Unpublished master's thesis). Université Jean Monnet Saint-Etienne, France.

Pochon, A., Arellano, R., \& Arráez, J. (2007). Analysis of a 3D sculling path in a vertical body position under different load conditions. In R. A. Colomina, J. A. Sánchez, F. N. Valdivielso, E. M. Ortiz, \& G. L. Contreras (Eds.), Swimming Science I (pp. 239-244). Granada: Editorial Universidad de Granada.

Rostkowska, E., Habiera, M., \& Antosiak-Cyrak, K. (2005). Angular Changes in the Elbow Joint during Underwater Movement in Synchronized Swimmers. Journal of Human Kinetics, 14, 51-66.

Sanders, R. (1999). Hydrodynamic characteristics of a swimmer's hand. Journal of Applied Biomechanics, 15, 3-27.

Schleihauf, R. (1979). A hydrodynamic analysis of swimming propulsion. In J. Terauds \& E. W. Bedingfield (Eds.), Swimming III (pp. 70-109). Edmonton: University of Alberta.

Thomas, D. G. (1990). Advanced Swimming: steps to success. Champaign: Leisure Press.

Winter, D. (2005). Kinematics. In D. Winter, Biomechanics and Motor Control of Human Movement (pp. 13-58). New Jersey: John Wiley \& Sons.

\section{Authors' note}

Lara Elena Gomes is affiliated with the Federal University of Vale do São Francisco and Federal University of Rio Grande do Sul.

Mônica de Oliveira Melo is affiliated with the Federal University of Rio Grande do Sul and University of Caxias do Sul.

Victor Wigner Tremea is affiliated with the Federal University of Rio Grande do Sul.

Marcelo La Torre is affiliated with the Federal University of Rio Grande do Sul, University of Caxias do Sul, and University of Vale do Rio dos Sinos 
Yumie Okuyama da Silva is affiliated with the Caruaruense Association of Higher and Technical Education, and Brazilian Institute of Management and Marketing

Flávio de Souza Castro and Jefferson Fagundes Loss are affiliated with the Federal University of Rio Grande do Sul

\section{Corresponding author:}

Lara Elena Gomes

Colegiado de Educação Física, UNIVASF

Av. José de Sá Maniçoba S/N, Centro, 56304-917 Petrolina, Pernambuco, Brasil.

Telephone: +55 (87) 2101-6856

Fax: +55 (51) 3308-5843

E-mail: lara.gomes@univasf.edu.br

Manuscript received on May 30, 2013

Manuscript accepted on January 11, 2014

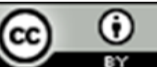

